\title{
BIM 技术在建筑工程管理中的应用
}

\author{
童国友 \\ 浙江中环建设监理有限公司 \\ DOI:10.32629/btr.v2i11.2642
}

[摘 要] 目前,我国各种建筑工程的数量和规模正在扩大。项目本身的建设周期较长,资金投放较大,在日益激烈的社会竞争中,如何能在我国占 据主导地位并获得经济效益, 已成为建筑单位重点考量的核心内容。本文就对建筑工程管理中 BIM 技术的应用进行分析, 希望对建筑行业发展 有所帮助。

[关键词] BIM 技术；建筑工程管理；经济效益

建筑工程本身就是一项复杂且系统的建设项目, 施工中存在的影响因 素较多, 要想保证施工质量, 就需要对施工各环节进行综合考量, 并制定科 学合理的管理方案, 以推动工程建设的顺利进行。将BIM技术应用到建筑工 程管理中, 能够有效实行施工资源的整合与调配, 为工程建设提供帮助。

\section{1 建筑信息模型}

建筑信息模型简称BIM, 是建筑学、工程学及土木工程中的新型辅助工 具, 其是以三维图形为主导, 结合建筑学、计算机技术的相关知识, 为建筑 设计及管理提供辅助的重要工具。

\section{BIM 技术的特点}

将BIM技术应用到建筑工程管理中, 实现了工程全生命周期的管控, 便 于工作人员对各阶段施工内容实行全方位的监管, 获取较为精准的信息数 据。通过对该项技术应用效果的分析, 其具备的特点有:

2. 1全面性: 利用BIM构建的三维模型可将建筑工程的各个环节予以直 观、立体的展现, 便于工作人员结合施工具体情况改善设计图纸和方案, 增强施工的准确性。

2. 2 高效性: 在BIM构建的三维模型中, 可直接对工程建设中涉及的各 项参数数据进行修改和调整, 并在此基础上, 完善施工内容, 规划施工流程, 处理施工中可能出现的各种问题, 加强设计的科学性、可行性。

2. 3立体性: 以往工程建设中, 图纸都是以二维图形的模式呈现的, 且各 设计构造之间存在独立性, 在连接操作中很难保证施工环节的有效性, 这不 仅增加了施工难度, 也为工程建设埋下了较多隐患。而采用BIM技术后, 三 维模型会将施工各环节直观展现出来, 为工程建设规划提供可靠依据。

\section{BIM 技术在建筑工程管理中的应用}

3. 1在质量管理中的应用: 质量一直都是建筑企业关注的重点, 一旦出 现质量问题, 不仅建筑自身的功能得不到充分发挥, 还会缩短建筑使用寿 命, 为社会和企业带来较大的经济损失。所以应加大对建筑工程质量管理 的重视力度, 合理应用BIM技术, 提高质量管理水平。

3. 2 事前质量管理中BIM的应用: 在事前质量管理中应用BIM技术, 可通 过三维模型的构建对各阶段施工中存在的问题予以及时发现和解决, 然后 采取有效的处理措施, 改进工程质量。与此同时, 对工程建设项目进行碰撞 检查, 找出存在的问题, 并加以改善, 完善工程建设方案。此外, 在事前质量 管理中, BIM技术也可对预留孔洞、构建配筋等配置的合理性实行检查, 避 免发生返工。

3. 3 事中质量管理中的应用: 事中质量管理是提高工程建设质量的关 键环节, 在该环节应用BIM技术的优势为: 首先, 利用BIM的可视化功能可对 节点构造予以模拟, 并将其直观展现出来, 为工作人员材料及施工工艺的 规划提供保障。如模拟钢筋节点结构, 帮助施工人员确定钢筋位置等。

其次, 加强预留孔洞尺寸、位置定位的准确性。在管线布局设置中,
通过BIM软件的应用可对管线排布方式予以确定, 并通过自动定位功能的 应用, 准确定位管线安装中所需的预留孔洞位置, 确保孔洞预留的合理性。

最后, 合理分析质量问题。现场施工质量管理人员可通过专业设备对 现场实际情况实行准确记录, 并在数据整合后将其传输到BIM数据库中, 便 于其随机调取和应用。在出现质量问题时, 相关人员只需对现有数据信息 进行查阅及现场照片的分析, 找出质量问题产生的原因, 然后制定科学合 理的管控措施, 提高施工质量。例如, 现场管理人员可利用智能手机将钢 筋、混凝土现场施工情况, 通过图片的形式传输到BIM数据库中, 并提交相 应的质量检测报告, 当出现质量问题后, 通过这些数据资料的细致分析, 可 找出问题原因, 然后提出合理解决方案, 减少危险的发生。

3. 4 在安全管理中的应用: 安全管理与质量、进度、成本管理之间存 在着紧密联系。加强安全管理能够降低工程建设中安全事故的发生概率, 降低成本支出。为此, 在安全管理中, 应加强BIM的应用, 利用虚拟技术开展 安全管理, 准确识别工程中存在的安全风险, 然后有针对性采取相关措施。 具体来说, BIM在安全管理中的应用为:

一是借助虚拟施工开展安全管理。在建筑工程安全管理中, 借助虚拟 技术对施工作业进行预演, 能够对可能出现的安全问题实行预测, 实现安 全事故的合理分析, 从而优化现有施工方案。在预测安全问题时, 主要是通 过人际交互技术, 对可能导致安全事故的因素及事故发生后的后果予以预 测和分析。如高空坠落、塔吊伤亡事故等, 从而配备合理的安全防护措施, 实现提前预防和控制。在分析安全事故时, 主要是结合以往事故分析报告, 总结经常出现的事故类型, 让施工人员明确事故发生的后果, 加深施工人 员的安全意识。然后根据现有条件及工程建设要求, 对其实施预防和处理, 避免类似问题的再次发生。

二是安全识别与防护。通过对建筑安全事故的分析可知, 临边洞口是 事故的高发区域,一般情况下, 为了降低事故率, 会采用防护栏或安全网的 设置对其进行保护, 不过在此之前需要识别临边洞口, 并对需要防护的区 域予以确定, 这时就需要利用BIM, 来保证识别及防护区域位置确定的准确 性、可靠性, 便于后续防护工作的开展。由于建筑工程具有规模大的特点, 所以需要保护的临边洞口数量较多。利用BIM技术可在最短时间内排查临 边洞口, 并将其具体情况展现出来, 便于防护方案的制定。

3. 5 在工程进度管理中的应用: BIM在工程进度管理中的应用分为三部 分, 其一, 对工程进度的预测。利用BIM预测工程进度时, 需先建立完善的三 维信息模型, 并根据现有数据信息对模型实行不断优化和调整,注重其准 确性。且按照施工方案进行整个工程操作的模拟, 查看其是否与进度控制 要求相符, 如果发现问题, 要及时调整和改进, 达到进度控制目标。同时, 在运用BIM预测工程进度的过程中, 可按照施工组织设计对施工过程实行 三维模拟, 检查施工组织设计是否与进度控制要求相符, 若存在不符的情 


\title{
净水构筑物防渗堵漏施工技术解析
}

\author{
杽金菲 ${ }^{1}$ 刘妍 ${ }^{2}$ \\ 1 江苏扬建集团有限公司 2 扬州市上善建设工程有限公司 \\ DOI:10.32629/btr.v2i11.2607
}

[摘 要] 随着我国社会经济的持续发展,人们对生活饮用水的质量提出更高的要求,如何更好的满足人们需求,是净水厂关注的重点。其关键在 于如何保证净水构筑物良好运作,提升生产效率。防渗堵漏施工技术的应用是提升净水构筑物稳定性运行关系。基于此, 本文结合理论实践,在 简要阐述净水构筑物防渗堵漏技术发展现状的基础上, 分析了防渗堵漏的要点, 并提出具体的应用途径, 希望对我国净水构筑物高效稳定运行有 一定帮助。

[关键词] 净水构筑物; 防渗堵漏; 促凝灰浆; 直接堵塞

净水构筑物是净水厂的主要组成部分, 同时整个水处理工艺的关键载 体, 加强对净水构筑物维护管理, 合理应用防渗堵漏技术, 是净水厂管理的 主要工作。对净水处理的质量有严重影响。基于此, 开展净水构筑物防渗 堵漏施工技术的解析就显得尤为必要。

\section{1 净水构筑物防渗堵漏施工发展现状}

净水厂要想提升经济利益, 并保证居民饮用水的安全性, 就必须提升 净水构筑物防渗堵漏施工质量, 科学合理的应用防渗堵漏施工技术, 可有 效提升净水构筑物的预防管理力度。所以, 净水厂在经营发展过程中, 形成 了多种防渗堵漏施工技术和材料, 如: 混凝土、砂浆、填充固结等都是净 水构筑物防渗堵漏的主要材料。在进行灌浆堵水施工中, 应用最广泛的材 料为水泥浆。

\section{2 净水构筑物防渗堵漏施工技术应用要点分析}

2. 1 精确定位渗漏水源

为最大限度上提升, 净水构筑物防渗堵漏施工效率, 保证净水效果, 提 升水质质量。就必须先精确定位渗漏水源。渗漏水源和渗漏点之间存在密 切联系, 并非一一对应的关系。所以, 在进行净水构筑物防渗堵漏施工时,

况, 则需及时调整, 并根据进度控制方法, 准确预测工期。

其二, 工程进度的管理。BIM对工程进度的管理分为实时控制和动态控 制两部分。实时控制就是按照进度管理要求, 利用BIM对现场施工的具体情 况进行了解和掌握, 并通过与设计方案的对比, 找出其中存在的偏差事项, 实行合理优化和改进, 避免不良因素拖慢工期。

动态控制是要求相关人员在BIM模拟技术的基础上, 对现场施工实行 动态化的管理和控制, 在保证施工作业有序进行的同时, 合理控制施工进 度, 确保工程在规定时间内完工。在进度管理和控制中, 可按照施工组织设 计及方案, 在BIM模型中为各构件添加时间属性, 加强模型与方案间的联系 性, 再通过三维动态演示, 现场管理人员便可据此对各个工序的进展情况 予以检查和对照。

其三, 工程量控制。工程量与工程进度管理之间存在着密切联系, 为实 现进度管理目标, 在工程量控制中, 合理应用BIM技术, 加大动态化管控力 度是尤为必要的。这就要求工作人员在施工中先对工程量进行查询, 之后 通过与进度计划的对比, 确定实际完成工程量的情况, 然后找出偏差产生 的原因, 采取合理可行的方法和措施, 完成工程的优化和调整, 从而使工程 量的完成情况与进度计划相符。

3. 6 在造价管理中的应用: 利用BIM技术对工程造价管理所需资料进行 存管, 不仅方便管理人员调取资料, 也能实现文件资料的统一化管理, 为成 本预算、签证及款项支付等管理工作的开展提供依据。在工程建设中, 众
需要在精确定位渗漏水源的基础上, 精确判断二者之间的联系, 为后期施 工提供数据支持和理论指导。找准水源是净水构筑物防渗堵漏施工的关键 工序, 需要相关人员高度重视, 净水构筑物发生渗漏的原因比较多, 既可能 单一某处发生渗漏水, 也可能存在多处渗漏, 甚至有的渗水位置和水源间 距比较大, 如果找不准漏水水源, 哪里渗漏就补哪里, 可能起到治标不治本 的防渗堵漏现象, 造成大量人力、物力、财力的无故浪费。

在寻找漏水水源时, 要进行 “引堵结合”的原则, 要有计划、有目的性、 有针对性的堵水, 才能从根本上找到水源, 解决净水构筑物渗漏水问题。盲 目堵水, 会引起水无出路的问题, 这样的处理方法, 极易导致其他薄弱位置 发生渗漏水问题, 发生 “这里堵, 哪里漏, 防不胜防” 的局面。除此之外, 无计划、无目的的堵水, 还会造成净水构筑物内部水压超标等问题发生, 也不符合设计标准, 对建筑物的安全造成严重隐患。

2. 2 选择合理的施工材料

在净水构筑物防渗堵漏施工中, 科学合理的选择施工材料, 提升防渗 堵漏施工质量的关键, 同时也是保证净水构筑物得以高效运行的基础。因 此, 在选择防渗堵漏施工材料时, 既要从质量上严格把控, 也要对施工材料 料所占资金费用最大，而这也是造价管的首要内容，利用BIM 技术对材料采购、使用等进行有效管理, 能够降低材料自身及成本上的浪 费, 减少问题的产生。与此同时, BIM的应用还可加强材料分配的合理性, 规划员工材料使用规范, 避免问题的产生。

基于BIM数据库, 审核人员可以在BIM数据库中查取同类建设工程的历 史数据, 然后运用BIM进行多维度模拟计算, 即使是小到一个细部的施工消 耗标准也能被快速的分析、汇总及输出, 实现真正的限额领料。BIM平台的 合理应用, 实现了人力、物力、财力的科学划分, 提升了资源利用率, 且维 持了使用的均衡性。同时, 在施工组织中可高效地实施穿插流水施工, 确保 各工序紧密衔接, 避免窝工情况的出现, 降低工程成本。

\section{4 结语}

基于BIM的强大功能, 将其应用在建筑工程管理中, 一方面可以保证各 项管理工作及措施的高效落实, 提高施工质量; 另一方面可实现施工中资 源的合理调配, 规范施工人员的行为, 以此减少浪费及损失的形成, 为建筑 工程经济效益做出贡献。

\section{[参考文献]}

[1] 赵德贤.BIM技术在建筑工程管理中的应用分析 [J]. 科技 风,2019(26):139.

[2]张驰.浅析BIM在建筑工程管理中的应用[J].中国新技术新产品,2019(08):93. [3]侯蓉.BIM 技术在工程管理中的应用探讨 [J].居舍,2019(27):54. 